over the counter in Britain may also eventually prove to have serious toxic effects; vitamin $A$ in excess is already an established hepatic toxin. Liver injury has also resulted from eating Vicia faba beans and cereals contaminated with Penicillium and groundnuts with Aspergillus flavus, and from abuse of the fungi Amanita phalloides and Helvella.

The toxicity of self-administered medicaments is often difficult to determine, however, because their exact constituents are not disclosed. Manufacturers should be obliged to give a factual description of these-which would also help to dispel the mystique that all too often surrounds "fringe" medicines.

${ }^{1}$ Haubrich, W S, in Gastroenterology, vol 3, ed H L Bockus. Philadelphia, Saunders, 1965.

${ }^{2}$ Sherlock, S, Diseases of the Liver and Biliary Systems, 5th edn. Oxford, Blackwell, 1975.

3 Morrison, A S, Jick, H, and Ory, H W, Lancet, 1977, 1, 1142.

* Sherlock, S, Lancet, 1978, 2, 364.

${ }^{5}$ Reynolds, T B, Peters, R L, and Yamada, S, New England fournal of Medicine, 1971, 285, 813.

${ }^{6}$ McHardy, G, and Balart, L A, fournal of the American Medical Association, 1970, 211, 83.

7 Tolman, K G, Hammar, S, and Sannella, J J, Annals of Internal Medicine, 1976, 84, 290.

${ }^{\star}$ Blewitt, R W, et al, Gut, 1977, 18, 476.

9 Baerg, R D, and Kimberg, D V, Annals of Internal Medicine, 1970, 73, 713.

${ }^{10}$ O'Brien, E T, Yeoman, W B, and Hobby, J A E, British Medicalfournal, $1971,2,29$.

${ }^{11}$ Hill, K R, et al, West Indian Medical fournal, 1951, 1, 49.

12 Stuart, K L, and Bras, G, Quarterly fournal of Medicine, 1957, 26, 291.

${ }_{13}$ McLean, E K, Pharmacological Reviews, 1970, 22, 429.

${ }^{14}$ Datta, D V, et al, Postgraduate Medical fournal, 1978, 54, 511.

\section{The therapeutic pendulum and the special care baby unit}

Whenever a potent new drug becomes available its place in clinical practice tends to be established in three phases. Firstly, there is excessive enthusiasm; secondly, after the recognition of adverse effects, there is a rebound aversion; only then and finally is a balanced assessment made of its benefits and disadvantages. That a similar process may apply to things other than drugs is shown by the recent history of special care baby units (SCBUs), though in this case we hope we can avoid the second phase.

The 1960s and early 70s saw a proliferation of special care baby units in Britain, and the proportion of babies admitted to them increased from $6.2^{\circ} \%$ of all live births in 1964 to $18.4 \%$ in $1975 .{ }^{1}$ In 1964 the neonatal mortality rate in England and Wales for infants weighing $2500 \mathrm{~g}$ or less was $127.5 \mathrm{per}$ 1000 and for infants weighing over $2500 \mathrm{~g}$ it was 6.0 per 1000 live births. ${ }^{2}$ In 1974 the corresponding figures were 98.5 and 5.0 per 1000 live births. Since less than $7 \%$ of all babies weigh $2500 \mathrm{~g}$ or less at birth ${ }^{2}$ most infants now admitted to SCBUs are clearly not of low birth weight. In Exeter between 1967 and $19719.6 \%$ of liveborn babies weighing over $2500 \mathrm{~g}$ at birth were admitted to the SCBU, and Brimblecombe and his colleagues ${ }^{3}$ have argued that in retrospect many of these admissions were unnecessary. They looked at the causes of handicap detected at 5 years of age and claimed that in babies weighing over $2000 \mathrm{~g}$ at birth special care facilities could do little to reduce the incidence of handicap. ${ }^{3}$ In Cambridge the proportion of babies of birth weight greater than $2500 \mathrm{~g}$ admitted to the SCBU was reduced from $24 \%$ to $5 \%$ by altering admissions policies in $1975 .^{14}$

In this issue (page 583), Vaizey and Oppé report their findings from a survey of all admissions to 17 SCBUs in the North-west Thames region in the first three months of 1975. Seventy per cent of the babies admitted to the SCBUs weighed over $2.5 \mathrm{~kg}$ at birth, and nearly $40 \%$ were admitted for observation only, needed no special investigation or treatment, and left the unit within three days. A separate study carried out at the same time in London ${ }^{5}$ showed that because of inadequate facilities many of the SCBUs in question could not provide high-quality care for very sick babies.

Very sick newborn babies and small premature babies need special observation by specialist nurses, and undoubtedly these babies should be cared for in an SCBU. There is ample evidence that the intensive care (as distinct from special care) of very-low-birthweight babies is rewarding in terms of both mortality and morbidity, ${ }^{6-8}$ but such care can reasonably be provided only in the larger maternity units with adequate staff and equipment.

The evidence now points to an overuse of SCBUs for larger babies, and a recent publication in the series "Clinics in Developmental Medicine"9 has reminded us of the dangers that may arise from this unnecessary separation of so many mothers and babies. Among the dubious reasons for admission to the special care unit are caesarean section, forceps delivery, multiple deliveries, mild asphyxia, smallness for dates, mild or moderate jaundice, and minor feeding problems.

If minor problems in the newborn are to be managed on the postnatal wards then some of the medical and nursing skill which has been concentrated in the SCBUs will have to be directed back to the wards. Medical staff will need to be prepared to spend more time in the postnatal wards, and in many places present levels of staffing may make this difficult. At the same time nursing staff on postnatal wards will need to accept more responsibility for the care of the newborn.

One suggestion $^{1}$ that has emerged from the current debate is that the number of special care cots should be reduced from the present nationwide level of 6.5 per 1000 deliveries to 3 or 4 per 1000 deliveries. If this is done, many units will be left with space to spare, and in smaller units with 2000 or fewer deliveries per year there may be difficulty in keeping trained nursing staff unless they are given extra duties. The extra space might be used to provide accommodation for mothers near to the babies-for there is a strong case for establishing intermediate or transitional care areas outside the SCBUs, where mothers and babies can remain together but nursing staff cover is adequate to deal with minor problems.

Each unit will need to formulate its own policy according to local circumstances, and in some the standard of baby care which can be provided on the postnatal ward may be such that it may be safer to transfer a mildly sick baby to the SCBU. What should not be forgotten is that the most reliable observer of the baby may often be the mother-if she is allowed to be aware of the problem. The evidence pointing to the importance of early contact between mother and baby cannot be ignored, ${ }^{10}$ and a decision to transfer a baby to the SCBU should imply that the doctor considers that the danger to the baby of staying with his mother outweighs the desirability of close early contact.

The final sentence of the monograph by Brimblecombe, Richards, and Roberton" is worth quoting in full: "It must never be forgotten that, ultimately, the care of even very sick newborns is the responsibility of the parents and that 
medical and nursing staff exist to assist them in doing what needs to be done while not usurping the parents' role."

\footnotetext{
${ }^{1}$ Richards, M P M, and Roberton, N R C, in Separation and Special Care Baby Units (Clinics in Developmental Medicine, No 68), ed F S W Brimblecombe, M P M Richards, and N R C Roberton, chap 7. Spastics International Medical Publications, London and Philadelphia, Heinemann and Lippincott, 1978.

${ }^{2}$ Committee on Child Health Services (chairman Professor S D M Court), Fit for the Future. London, HMSO, 1976.

${ }^{3}$ Brimblecombe, F S W, et al, in Separation and Special Care Baby Units (Clinics in Developmental Medicine, No 68), eds F S W Brimblecombe, M P M Richards, and N R C Roberton, chap 6. Spastics International Medical Publications. London and Philadelphia, Heinemann and Lippincott, 1978.

4 Roberton, N R C, Archives of Disease in Childhood, 1977, 52, 819

5 Alberman, E, et al, British Medical fournal, 1977, 2, 1045.

${ }^{6}$ Kitchen, W H, et al, Developmental Medicine and Child Neurology, 1978, 20, 605 .

7 Stewart, A L, and Reynolds, E O R, Pediatrics, 1974, 54, 724.

8 Davies, P A, and Stewart, A L, British Medical Bulletin, 1975, 31, 85.

9 Separation and Special Care Baby Units (Clinics in Developmental Medicine, No 68), eds F S W Brimblecombe, M P M Richards, and N R C Roberton. Spastics International Medical Publications. London and Philadelphia, Heinemann and Lippincott, 1978.

10 Klaus, $\mathrm{M} \mathrm{H}$, and Kennell, $\mathrm{J} \mathrm{H}$, in Recent Advances in Paediatrics, no 5 , ed D Hull. Edinburgh, Churchill Livingstone, 1976.
}

\section{Epilepsy and learning}

At least 60000 schoolchildren in Britain have epilepsy ${ }^{1}$ and most of them are educated in ordinary schools. Learning and behaviour problems are more common in epileptic than in normal children, and a recent study from Oxford ${ }^{2}$ attempted to identify the children at greatest risk of problems at school. Boys but not girls seemed predisposed to a range of behavioural complications, but whether this was a biological phenomenon or socially determined remained uncertain. A persistent left temporal spike discharge was associated with backwardness in reading, inattentiveness, emotional dependence, and overactivity.

The possibility that the type and site of epileptic discharges are related to a particular behaviour disorder in children has only rarely been considered before. Nuffield ${ }^{3}$ noted that children with 3-per-second spike-and-wave discharges were shy, retiring, or neurotic; in contrast, those with temporal lobe spike discharges were aggressive or antisocial. In those studies, however, neither the side of the lesion nor sex was included in the analysis. Flor-Henry ${ }^{4}$ described severe forms of behaviour disturbance in adults with left temporal lobe lesions. McIntyre et $a l^{5}$ claimed that young adult patients with right temporal spike discharges were more impulsive than those with left temporal spike discharges; while Lishman ${ }^{6}$ suggested that left temporal lobe dysfunction in adults was particularly associated with psychiatric complications.

For many children the drugs used in treatment cause more school problems than the fits. In the Oxford study treatment with phenytoin was associated with poor reading, confirming studies from the same unit that had shown the harmful effects of the drug on intelligence and behaviour. ${ }^{7}$ Unfortunately, the drug concentrations in the blood were not measured routinely and there was no attempt to monitor compliance in any other way. The high incidence of behaviour disorders, particularly aggressiveness, in young children receiving phenobarbitone has persuaded many paediatricians to avoid this drug in epilepsy. ${ }^{8}$ Teachers in ordinary schools have very little medical knowledge, and disturbed behaviour or poor progress may be considered an inevitable effect of epilepsy or of effective drug treatment. The dozing child at the back of the class in the afternoon session may be a welcome respite to the teacher who has been contending with an aggressive rebel all morning. School medical officers and educational psychologists may assume that the child is having optimal care simply because he has appointments for an outpatient clinic-yet these visits may amount to nothing more than a cheerful greeting from the new paediatric house physician and a repeat prescription.

Many children with epilepsy will grow up to become adults with epilepsy, and their possible occupations will be restricted. They are more likely to be employable if they are literate. It is therefore particularly important that epileptic children should learn well during their early years at school. Optimal management is not simply preventing fits. Most district hospitals can now routinely estimate blood concentrations of most anticonvulsants, and a child's drug concentrations should be checked if there are behaviour or learning problems. Many children are well controlled with phenytoin without side effects, and they should continue to receive it; but if there are substantial side effects sodium valproate should usually be substituted. Sodium valproate is the first choice in new patients, though the evidence of long-term effects on behaviour and educational progress is scanty. The common side effects are drowsiness, nausea, anorexia, or excessive appetite; but these are often temporary. Excessively high doses may cause thrombocytopenia.

School medical officers of the new style ${ }^{9}$ have a responsibility for particular schools, and their close contact with teachers should give them the opportunity to hear about these learning problems. Children with epilepsy attending hospitals are likely to visit a general paediatric clinic rather than a neurological clinic: the message from Oxford is that epilepsy is not just fits.

${ }^{1}$ Gulliford, R, Special Educational Needs. London, Routledge and Kegan Paul, 1971.

2 Stores, G, Developmental Medicine and Child Neurology, 1978, 20, 502

3 Nuffield, E J A, Fournal of Mental Science, 1961, 107, 438.

${ }^{4}$ Flor-Henry, P, Epilepsia. 1972, 13, 773.

${ }^{5}$ McIntyre, M, Pritchard, P B, and Lombroso, C T, Epilepsia, 1976, 17, 377

${ }^{6}$ Lishman, W A, British fournal of Psychiatry, 1968, 114, 373.

7 Stores, G, Developmental Medicine and Child Neurology, 1975, 17, 647.

8 Bower, B D, in Paediatric Therapeutics, ed H B Valman, p 51. Oxford, Blackwell Scientific, 1979

${ }^{9}$ Department of Health and Social Security, Health Services Development, Court Report on Child Health Services, 1978, HC(78)5. London, DHSS, 1978. 